\title{
Peripheral Blood Immunophenotyping and Cytochemistry Were Performed
}

National Cancer Institute

\section{Source}

National Cancer Institute. Peripheral Blood Immunophenotyping and Cytochemistry

Were Performed. NCI Thesaurus. Code C160487.

An indication that immunophenotyping and cytochemistry were performed on peripheral blood samples during the study. 